\title{
Effect of directional solidification process on microstructure and stress rupture property of a hot corrosion resistant single crystal superalloy
}

\author{
Liang Luo, Cheng-bo Xiao, *Jing-yang Chen, Qing Li, and Sheng-long Dai \\ Science and Technology on Advanced High Temperature Structural Materials Laboratory, Beijing Institute of Aeronautical \\ Materials, Beijing 100095, China
}

\begin{abstract}
The influences of different directional solidification processes, i.e., the high rate solidification (HRS) and liquid metal cooling (LMC), on microstructure and stress rupture property of DD488 alloy were investigated. The DD488 alloy was directional solidified by both HRS and LMC processes. The microstructure and stress rupture properties at $980{ }^{\circ} \mathrm{C} / 250 \mathrm{MPa}$ were investigated by using optical microscopy (OM), scanning electron microscopy (SEM), electron microprobe analyzer (EPMA), transmission electron microscopy (TEM) and stress rupture testing. The results indicated that the LMC process refined the primary dendrite arm and decreased the microporosity volume fraction and solidification segregations of $\mathrm{Cr}$ and $\mathrm{Co}$ in as-cast DD488 alloy. After standard heat treatment of $1,260^{\circ} \mathrm{C} / 4 \mathrm{~h}, \mathrm{AC}$ (air cooling) $+1,080^{\circ} \mathrm{C} / 4 \mathrm{~h}, \mathrm{AC}+870^{\circ} \mathrm{C} / 24 \mathrm{~h}, \mathrm{AC}$, the $\mathrm{Y}^{\prime}$ morphology in LMC alloy was more cuboidal than that in HRS alloy, and the $\mathrm{Y}^{\prime}$ volume fraction of LMC alloy was higher than that of HRS alloy. The stress rupture life at $980^{\circ} \mathrm{C} / 250 \mathrm{MPa}$ of HRS alloy was $76.8 \mathrm{~h}$, and it increased to $110.0 \mathrm{~h}$ in LMC alloy. The LMC process increased the stress rupture life due to the higher $\mathrm{y}^{\prime}$ volume fraction, more perfect rafting structure and finer interfacial dislocation networks.
\end{abstract}

Key words: DD488; superalloy; liquid metal cooling; high rate solidification; microstructure; property

CLC numbers: TG132.3 3 Document code: A

Article ID: 1672-6421 2019)01-008-06

\begin{abstract}
$\mathrm{N}$ i-based single crystal superalloy blades have been introduced in industrial gas turbines (IGTs) to meet the need of the increasing turbine inlet temperature ${ }^{[1,2]}$. Directional solidification is the main technology for the production of single crystal superalloy blades for IGTs. The traditional high rate solidification (HRS) method is used in the preparation of the single crystal blades. However, the temperature gradient at the front of solidification interface decreases sharply with the advancing of the solidification interface because the heat dissipation during solidification is mainly caused by heat conduction and heat radiation of the solidified part of the blade. In addition, the size and weight of single crystal IGT blades are usually several times as that of aero engine blades, which further complicates the precautions of casting defects ${ }^{[3]}$.

An effective way to reduce or eliminate casting
\end{abstract}

\footnotetext{
Male, born in 1979, Ph.D., Senior Engineer. His research interests mainly focus on superalloys and integrated computational materials engineering (ICME). He has published 32 papers

E-mail: jychen126@126.com
}

defects is to improve the temperature gradient. Liquid metal cooling (LMC) process as a powerful directional solidification (DS) technique is prospectively used to manufacture single crystal (SC) turbine blades. Previous studies have proved that compared to HRS process, using a low melting point liquid metal as the coolant during the LMC process has advantages such as higher temperature gradient, finer dendrite, fewer solidification defects, lower solidification segregation and higher mechanical properties in the preparation of large scale single crystal IGT blades ${ }^{[3-5]}$. Therefore, the research on the application of LMC process in the preparation of Ni-based single crystal superalloy has been more attractive in the past decades ${ }^{[6-10]}$.

Recently, Beijing Institute of Aeronautical Materials (BIAM) developed a first generation hot corrosion resistant Ni-based single crystal superalloy DD488 suitable for high-temperature structural material applications. To investigate the effect of different solidification processes on the microstructure and the stress rupture property of the DD488 alloy, in the present work, as a material for advanced industrial gas turbine blades and vanes, DD488 alloy was prepared by both conventional Bridgman (HRS) and LMC processes, and 
the microstructure and stress rupture property of the alloy were investigated and compared.

\section{Experimental procedure}

The nominal composition (wt.\%) of the DD488 alloy is shown in Table 1. The DD488 alloy was directionally solidified (DS) as single crystal bars (14 $\mathrm{mm}$ in diameter and $150 \mathrm{~mm}$ in length) by both HRS process and LMC process with assistance of liquid tin coolant. After standard aging treatment of $1260{ }^{\circ} \mathrm{C} / 4 \mathrm{~h}, \mathrm{AC}$ (air cooling) $+1080^{\circ} \mathrm{C} / 4 \mathrm{~h}, \mathrm{AC}+870{ }^{\circ} \mathrm{C} / 24 \mathrm{~h}, \mathrm{AC}$, the stress rupture specimens were machined with the dimension of the gauge section being $5 \mathrm{~mm}$ in diameter and $25 \mathrm{~mm}$ in length. Stress rupture testing was conducted at $980{ }^{\circ} \mathrm{C} / 250 \mathrm{MPa}$. In order to obtain statistically significant results, at least three specimens were used for determining the stress rupture property.

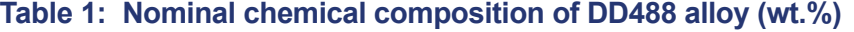

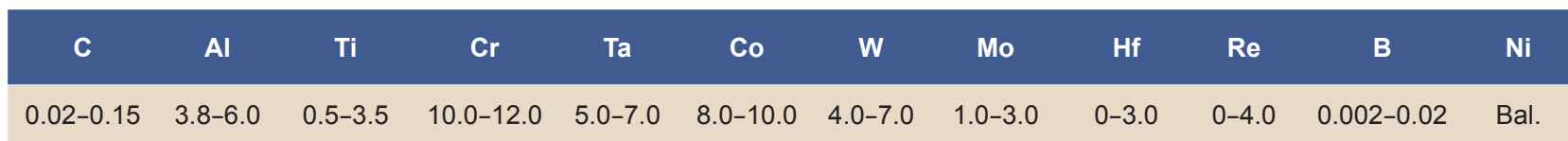

The metallographic specimens were mechanically polished and then etched with a solution of $1 \% \mathrm{HF}, 33 \% \mathrm{CH}_{3} \mathrm{COOH}$, $33 \% \mathrm{HNO}_{3}$ and $33 \% \mathrm{H}_{2} \mathrm{O}$. The microstructural examinations were performed using an optical microscope (OM) and a ZEISS SUPRA 55 field-emission scanning electron microscope (FESEM). The volume fraction of microporosity and $\gamma^{\prime}$ precipitate were determined using the standard point count method ${ }^{[11]}$. The average size of $\gamma^{\prime}$ phase was measured using Image-Pro Plus software.

The shape of precipitates was quantified by dividing the maximum Feret diameter by the minimum Feret diameter. Ideal cubes exhibit a Feret ratio of $\sqrt{2}$, while globular precipitate shapes result in a Feret ratio of about 1 . The $\gamma^{\prime}$ morphology is quadrate when the Feret ratio is greater than $\sqrt{2}^{[12]}$.

The dendritic segregation characteristics of the constituent elements were analyzed by quantitative segregation mapping using a JEOL JXA-8100 electron microprobe analyzer (EPMA) combined with a Scheil analysis. The detailed procedures of this technique have been reported by Tin et al. ${ }^{[13]}$. To assess the distribution coefficients $(k)$ of the individual elements, 225 quantitative point measurements were collected during EPMA segregation mapping in a square grid area $\left(\sim 1.2 \mathrm{~mm}^{2}\right)$ over a representative section of the dendritic microstructure. The composition data acquired for the individual elements were then ranked according to their characteristic segregation behavior. For elements having distribution coefficients greater than 1 , the composition data were ranked in descending order and plotted on an apparent fraction solid scale, yielding a Scheil plot. Composition data for elements segregating to the interdendritic regions were ranked in ascending order and plotted in the same manner. Distribution coefficients were then extracted by fitting the plots with a modified Scheil analysis, which accounts for back diffusion.

$$
C_{\mathrm{S}}=k C_{0}\left(1-(1-2 \alpha k) f_{\mathrm{S}}\right)^{k-1 / 1-2 \alpha k}
$$

where $C_{\mathrm{S}}$ is the local composition of the solid, $C_{0}$ is the nominal alloy composition, $\alpha$ is the Fourier number, and $f_{\mathrm{s}}$ is the fraction of solid.

The cross-sectional microstructures parallel to $<001>$ direction at about $6 \mathrm{~mm}$ away from fracture surface was examined after stress rupture. The perfection of the $\gamma / \gamma^{\prime}$ rafting structure was characterized by $\Omega$, which is represented by the following equation:

$$
\Omega=\left(P_{L}^{\perp}-P_{L}^{\|}\right) /\left(P_{L}^{\perp}+P_{L}^{\|}\right)
$$

where $P_{L}$ is the number of intersections per unit length and the terms $\|$ and $\perp$ denote scans in the directions parallel and perpendicular to the lamella, respectively.For an ideal rafting structure, $\Omega=1.0^{[14]}$. Specimens after stress rupture were also cut to thin slices perpendicular to the $<001>$ direction. A JEOL2010 transmission electron microscope was used for observation of the dislocation configurations.

\section{Results and discussion}

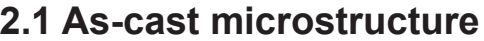

The as-cast optical microstructures of DD488 alloy prepared by HRS and LMC processes are shown in Fig. 1(a) and (b), respectively. The primary dendrite arm spacing of DD488 alloy prepared by HRS process was $323.9 \mu \mathrm{m}$, while it was 236.8 $\mu \mathrm{m}$ by LMC process, which was extensively refined, as shown in Fig. 1(b). The microporosity of the alloy prepared by HRS process was $0.27 \%$ (Fig. 2a) and it decreased to $0.13 \%$ (Fig. 2b) by LMC process.

The relationship among the primary dendrite arm spacing $\left(\lambda_{1}\right)$, temperature gradient $(G)$ and solidification rate $(V)$ is as follows ${ }^{[15]}$ :

$$
\lambda_{1} \propto G^{-\frac{1}{2}} \times V^{-\frac{1}{4}}
$$

In this study, the temperature gradient of the LMC process is higher than that of the HRS process. Therefore, the primary dendrite arm spacing of as-cast DD488 prepared by the LMC process was smaller than that of the HRS process. The microporosity decreased with the refinement of dendrite, which was consistent with the result reported by Bondarenko and Kablov ${ }^{[16]}$.

\subsection{Solidification segregation}

Figure 3 shows the distribution of $\mathrm{Cr}$ and Co elements in DD488 alloy prepared by both HRS and LMC processes. The solidification segregation was also affected by DS processes. The distribution coefficients $(k)$ of $\mathrm{Cr}$ and $\mathrm{Co}$ in the HRS 

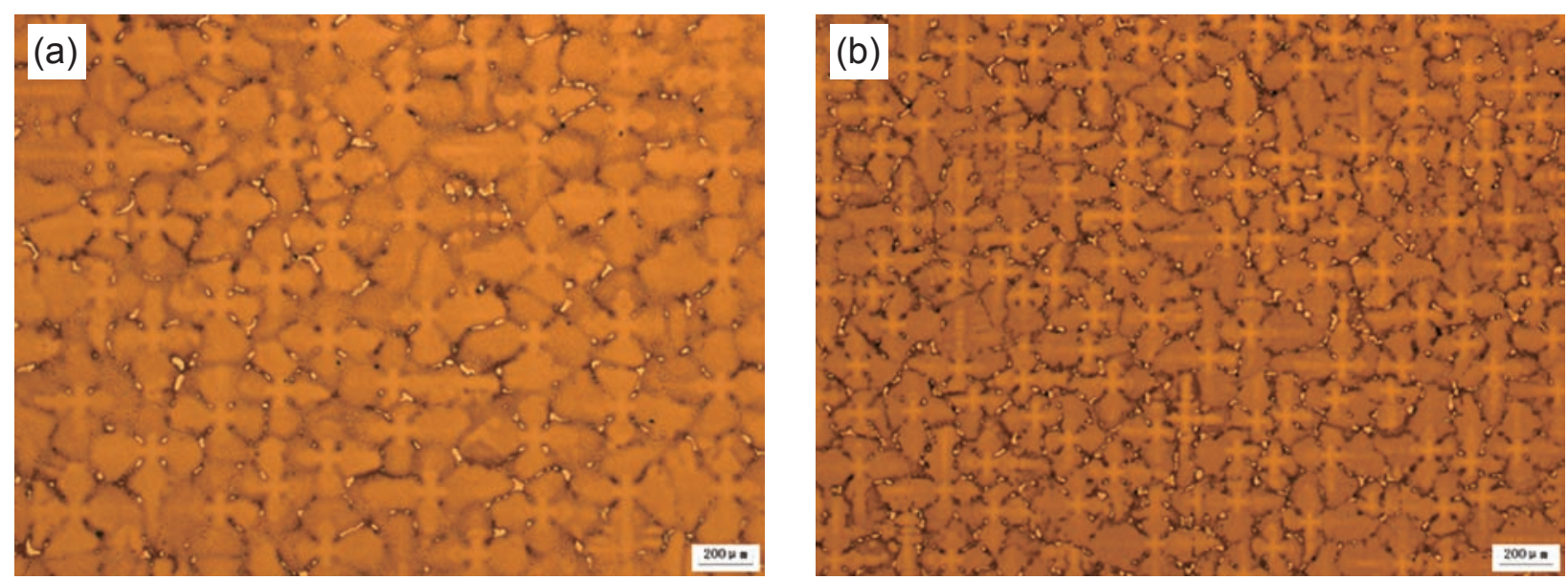

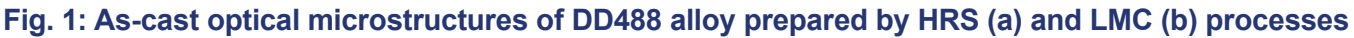

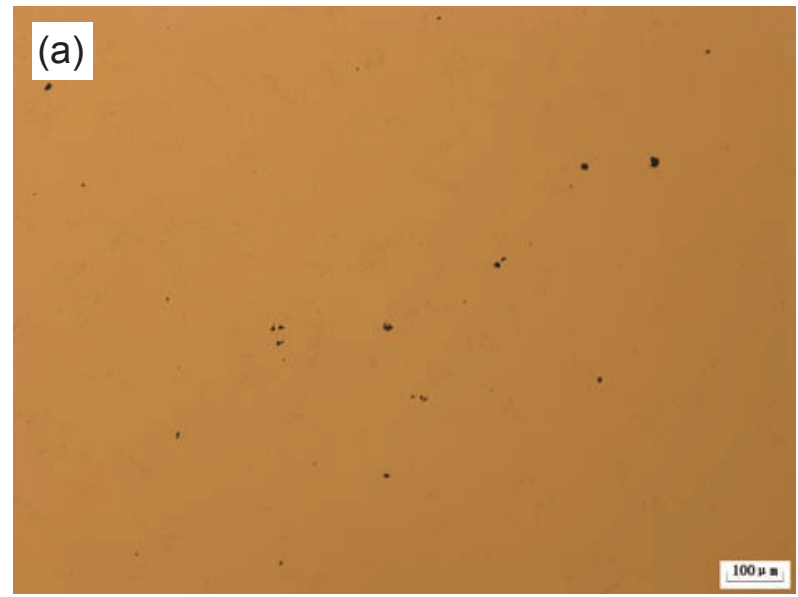

(b)

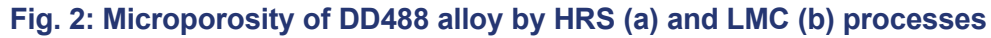
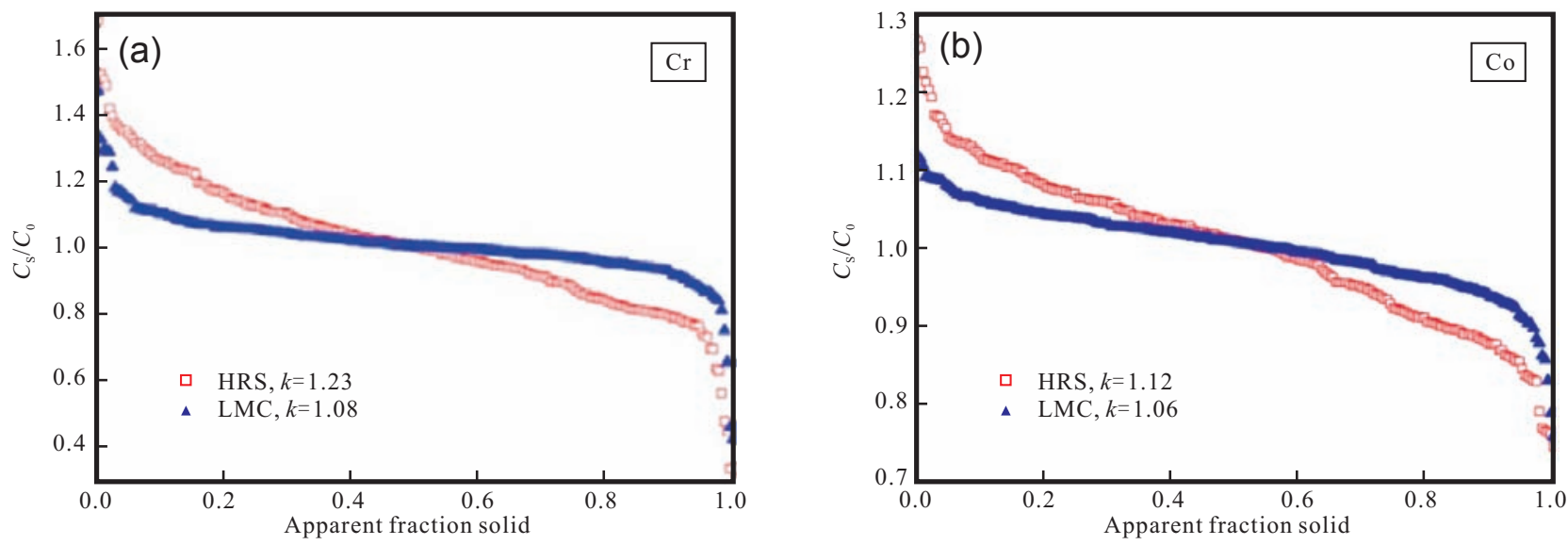

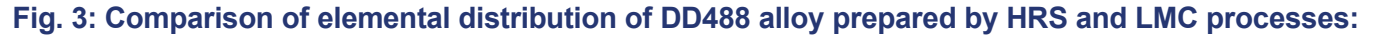

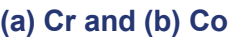

specimen were 1.23 and 1.12 , respectively. LMC process made the distribution of $\mathrm{Cr}$ and $\mathrm{Co}$ became more uniform. The distribution coefficients of $\mathrm{Cr}$ and $\mathrm{Co}$ in LMC specimen were 1.08 and 1.06, respectively. However, the distribution characteristics of other alloy elements were not obviously affected by the DS process, as shown in Table 2 .

The dendrite was refined by the LMC process significantly as shown in Fig. 1. Therefore, the diffusion distance of alloying elements in the LMC specimen was smaller than that of the HRS specimen, which was beneficial for the diffusion, and, as a result, decreased the distribution coefficients $k$ of $\mathrm{Cr}$ and $\mathrm{Co}$.

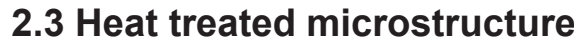

The typical microstructures of DD488 alloy prepared by HRS and LMC processes after standard heat treatment are shown in Fig. 4. The Feret ratios of $\gamma^{\prime}$ precipitate in specimens prepared 
Table 2: Distribution coefficients of DD488 alloy prepared by HRS and LMC processes

\begin{tabular}{llllllllll}
\hline LMC & $\square$ & $\square$ & $\mathrm{Ni}$ & $\square$ & $\square$ & $\square \square$ & $\square$ & \\
HRS & 0.94 & 0.80 & 0.98 & 0.78 & 0.85 & 1.08 & 1.32 & 1.06 & 1.12
\end{tabular}
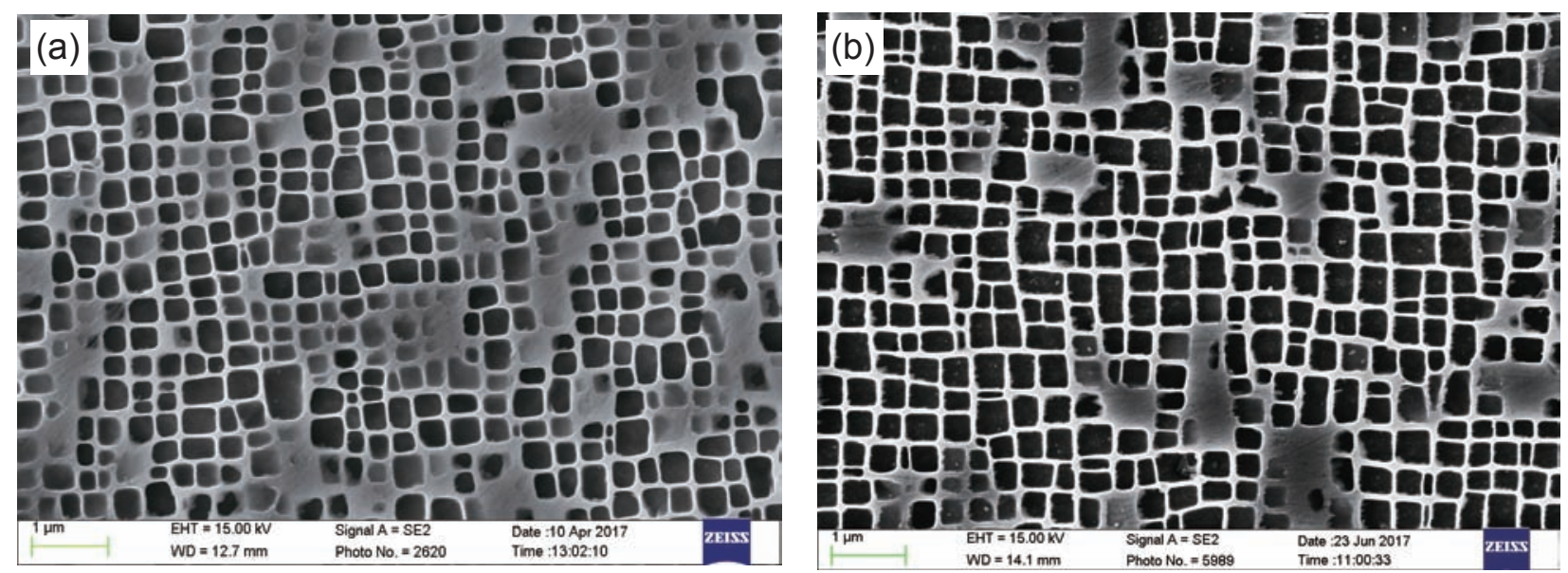

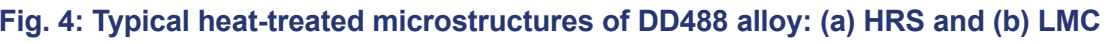

by HRS and LMC process after standard heat treatment were 1.31 and 1.37 , respectively, which means that LMC specimen had more cuboidal morphology of $\gamma^{\prime}$ precipitates than HRS specimen. The volume fractions of $\gamma^{\prime}$ precipitates in specimens prepared by HRS and LMC processes after standard heat treatment were $48.0 \%$ and $53.4 \%$, respectively.

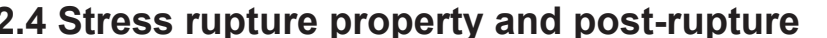

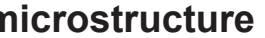

The average stress rupture life of specimens prepared by HRS process was $76.8 \mathrm{~h}$, and it increased to $110.0 \mathrm{~h}$ in specimens prepared by LMC process. Both kinds of specimens possessed good high-temperature ductility. The results of post-rupture microstructure investigation indicated that the value of $\Omega$ in specimens prepared by HRS and LMC processes was 0.40 and 0.62 , respectively, which indicated that the perfection of the $\gamma / \gamma^{\prime}$ rafting structure in specimen prepared by LMC process was higher than that prepared by HRS process, as shown in Figs. 5(a) and (b). Figures 6(a) and (b) show the $\gamma / \gamma^{\prime}$ interfacial dislocation networks after stress rupture in specimens prepared by HRS and LMC processes, respectively. It clearly indicated that the dislocation density in the $\gamma / \gamma^{\prime}$ interface of the specimen prepared by LMC process was much higher than that prepared by HRS process.

The present results indicated that the stress rupture property of DD488 alloy was influenced by directional solidification processes mainly through the changing of $\gamma^{\prime}$ volume fraction, rafting behavior during creep, and interfacial dislocation networks.

Ni-based single crystal superalloy usually consists of high volume fraction of ordered $\gamma^{\prime}$ precipitates (with a L12 structure) in coherence with the disordered FCC $\gamma$ matrix. Previous investigation indicated that the optimized volume fraction of $\gamma^{\prime}$ precipitates that result in the peak creep strength was at
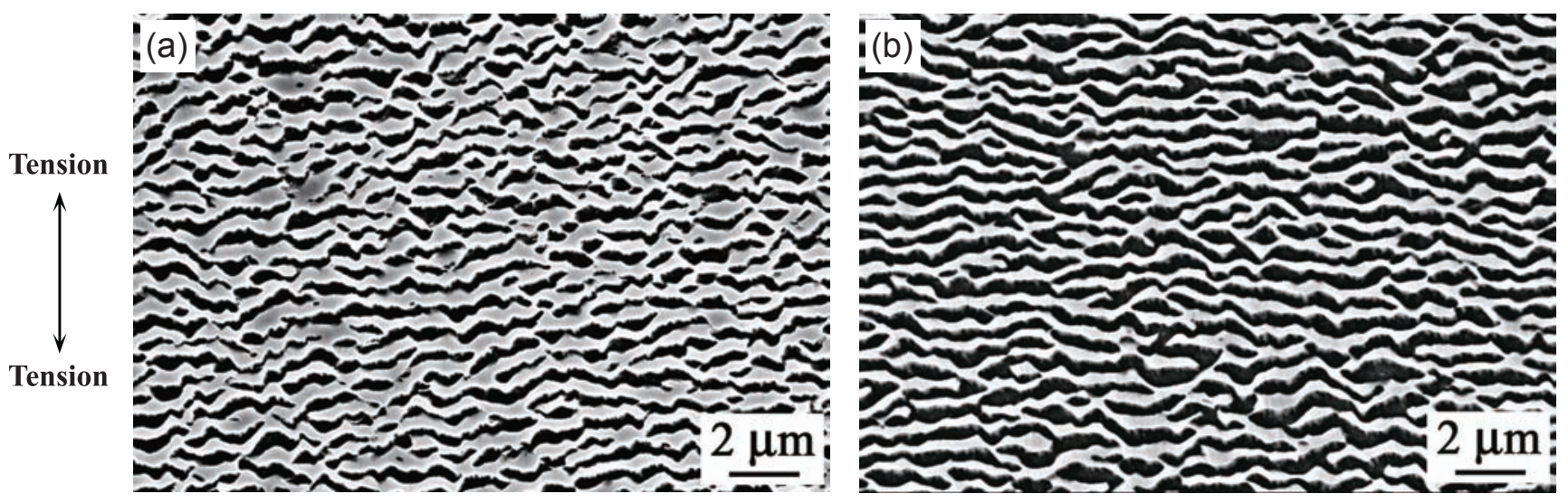

Fig. 5: $y^{\prime} \mathrm{y}^{\prime}$ rafting structure after stress rupture in specimen prepared by HRS (a) and LMC process (b) 

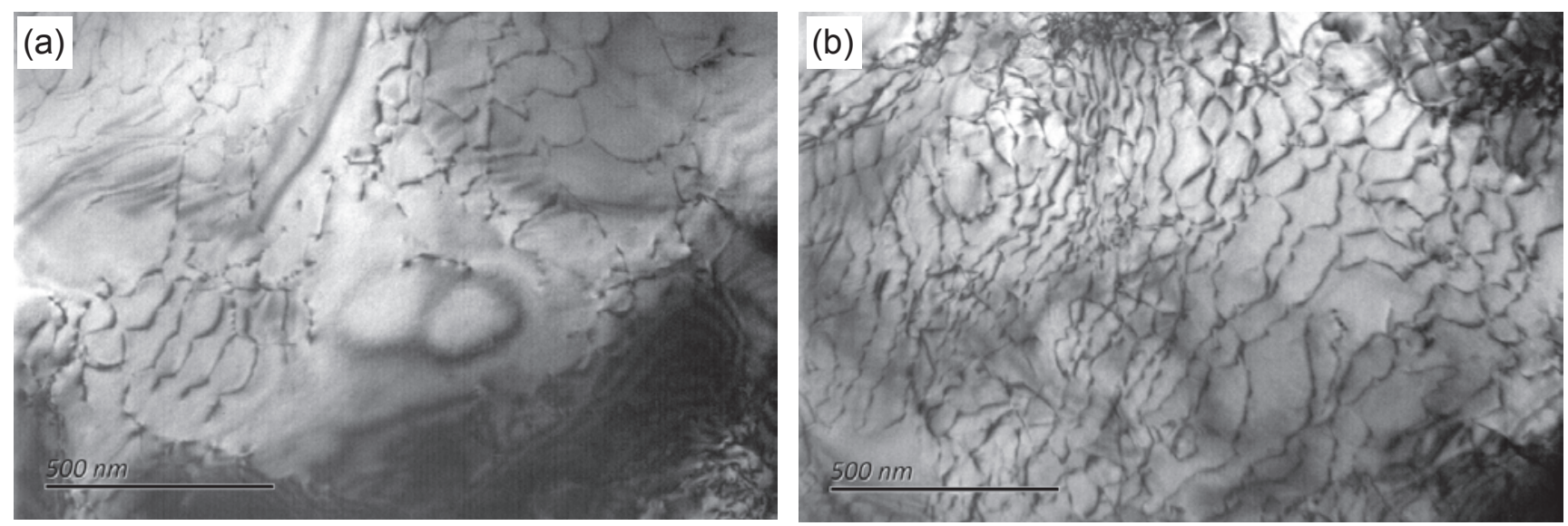

Fig. 6: $y / y^{\prime}$ interfacial dislocation networks after stress rupture in specimen prepared by HRS (a)

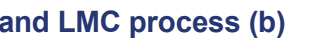

around $65 \%-70 \%$, and that the creep strength increased with increasing the $\gamma^{\prime}$ volume fraction when the volume fraction of $\gamma^{\prime}$ precipitates was less than $65 \%-70 \%{ }^{[17]}$. In the present study, the $\gamma^{\prime}$ volume fraction of alloy prepared by LMC process was higher than that of alloy prepared by HRS process (Fig. 4). So, the structural hardening induced by $\gamma^{\prime}$ precipitates was higher in the alloy prepared by LMC process compared with that in the alloy prepared by HRS process.

The lattice misfit between $\gamma$ matrix and $\gamma^{\prime}$ precipitates was reported to be the driving force for the rafting behavior during creep deformation, and could enhance the creep property, because the rafting structure would be an effective barrier for confining dislocation activity within the $\gamma$ rafts, which led to the steady state of the creep deformation ${ }^{[18]}$. Ni-based single crystal superalloys with raft perpendicular to the applied tensile stress have a negative lattice misfit, while the superalloys with raft parallel to the applied tensile stress have a positive lattice misfit. If the lattice misfit is eliminated, the rafting structure should not occur ${ }^{[19]}$. Zhang et al. ${ }^{[18]}$ reported that the $\gamma / \gamma^{\prime}$ interfacial dislocation networks play an important role during creep. The finer the interfacial dislocation networks, the smaller the minimum creep rate and the longer the creep life. In this study, the $\gamma / \gamma^{\prime}$ rafting structure in the alloy prepared by LMC process was more perfect than that prepared by HRS process [Figs. 5(a) and (b)]. Meanwhile, the interfacial dislocation networks in the alloy prepared by LMC process was finer than that prepared by HRS process [Figs. 6(a) and (b)]. Therefore, the stress rupture life of the alloy prepared by LMC process was higher than that prepared by HRS process.

\section{Conclusions}

(1) The primary dendrite arm spacing of DD488 alloy prepared by HRS process is $323.9 \mu \mathrm{m}$. LMC process refined the primary dendrite arm to $236.8 \mu \mathrm{m}$. In addition, LMC process can significantly decrease the microporosity volume fraction. The solidification segregations of $\mathrm{Cr}$ and $\mathrm{Co}$ are also decreased by LMC process.
(2) LMC alloy specimen has more cuboidal morphology of $\gamma^{\prime}$ precipitates than HRS alloy specimen. Also, the $\gamma^{\prime}$ volume fraction of heat treated LMC alloy was higher than that of HRS alloy.

(3) The stress rupture life of HRS alloy is $76.8 \mathrm{~h}$, and it increases to $110.0 \mathrm{~h}$ in LMC alloy. The increase of $\gamma^{\prime}$ volume fraction, rafting structure perfection and interfacial dislocation networks density by LMC process all contribute to the improvement of stress rupture life.

\section{References}

[1] Reed R C. The superalloys: Fundamentals and applications. Cambridge, UK: Cambridge University Press, 2006.

[2] Shah D M and Cetel A. Evaluation of PWA 1483 for large single crystal IGT blade applications. TMS, Superalloys, 2000: 295304.

[3] Elliott A J, Tin S, King W T, et al. Directional solidification of large superalloy castings with radiation and liquid-metal cooling: A comparative assessment. Metallurgical and Materials Transactions A, 2004, 35(10): 3221-3231.

[4] Zhang $\mathrm{J}$ and Lou L. Directional solidification assisted by liquid metal cooling. Journal of Materials Science and Technology, 2007, 23(3): 289-300.

[5] Elliott $\mathrm{A} \mathrm{J}$ and Pollock T M. Thermal analysis of the Bridgman and liquid-metal-cooled directional solidification investment casting processes. Metallurgical and Materials Transactions A, 2007, 38(4): 871-882.

[6] Giamei A F and Tschinkel J G. Liquid metal cooling: A new solidification technique. Metallurgical Transactions A, 1976, 7(9): $1427-1434$.

[7] Fitzgerald T J and Singer R F. An analytical model for optimal directional solidification using liquid metal cooling. Metallurgical and Materials Transactions A, 1997, 28(6): 1377-1383.

[8] Liu C, Shen J, Zhang J et al. Effect of withdrawal rates on microstructure and creep strength of a single crystal superalloy processed by LMC. Journal of Materials Science and Technology, 2010, 26(4): 306-310.

[9] Brundidge C L, Miller J D, Pollock T M. Development of dendritic structure in the liquid-metal-cooled, directional-solidification process. Metallurgical and Materials Transactions A, 2011, 42(9): 2723-2732. 
[10] Guo R F, Liu L, Li Y F, et al. Numerical simulation of temperature field and grain texture during casting single crystal superalloy DD403 with liquid metal cooling. Foundry, 2014, 63(2): 145151. (In Chinese)

[11] Ren H L. Metallographic experimental techniques. Beijing, China: Metallurgical Industry Press, 1986.

[12] Pyczak F, Devrient B, Neuner F C, et al. The influence of different alloying elements on the development of the $\mathrm{Y} /$ $Y^{\prime}$ microstructure of nickel-base superalloys during hightemperature annealing and deformation. Acta Materialia, 2005, 53(14): 3879-3891.

[13] Tin S, Pollock T M, Murphy W. Stabilization of thermosolutal convective instabilities in Ni-based single-crystal superalloys: Carbon additions and freckle formation. Metallurgical and Materials Transactions A, 2001, 32(7): 1743-1753.

[14] Nathal M V and Mackay R A. The stability of lamellar $Y-Y^{\prime}$ structures. Materials Science and Engineering, 1987, 85: 127138.
[15] Ma D X and Sahm P R. Primary spacing in directional solidification. Metallurgical and Materials Transactions A, 1998, 29(3): 1113-1119.

[16] Bondarenko Y A and Kablov E N. Directional crystallization of high-temperature alloys with elevated temperature gradient. Metal Science and Heat Treatment, 2002, 44(7-8): 288-291.

[17] Murakumo T, Kobayashi T, Koizumi $Y$, et al. Creep behaviour of Ni-base single-crystal superalloys with various $Y^{\prime}$ volume fraction. Acta Materialia, 2004, 52(12): 3737-3744.

[18] Zhang J X, Murakumo T, Harada H, et al. Dependence of creep strength on the interfacial dislocations in a fourth generation SC superalloy TMS-138. Scripta Materialia, 2003, 48(3): 287-293.

[19] Fährmann M, Hermann W, Fährmann E, et al. Determination of matrix and precipitate elastic constants in $\left(\mathrm{Y}-\mathrm{Y}^{\prime}\right)$ Ni-base model alloys, and their relevance to rafting. Materials Science and Engineering A, 1999, 260(1/2): 212-221.

This study was financially supported by the National Key R\&D Program of China (Grant No. 2016YFB0701402), National Natural Science Foundation of China (Grant No. 51771020) and Aeronautical Science Foundation of China (Grant No. 2015ZE21006). 